\title{
Guarding paediatricians against allegations of assault
}

\author{
T L Chambers, G P Panting
}

A colleague of TLC (not a paediatrician) recently performed an unchaperoned, somewhat intimate clinical examination on a young person. At the time, the consultation and examination appeared uneventful, but he was shocked and upset to learn subsequently that the young person had left the hospital and immediately gone to a police station to lodge a complaint of assault. After enduring inquiries and uncertainty lasting two monthsdescribed as easily the worst of his life-he was informed that police inquiries were no longer proceeding. No complaint was laid against him to his employer.

Another clinician with an exclusively paediatric practice had a complaint of genital assault against a young child made by the parents to his employer. Subsequent investigation revealed that this had arisen through mutual misunderstanding. Both doctor and parents (and, probably, the child) felt hurt and aggrieved by the incident, which was taken no further after an apology.

Paediatricians pride themselves on their relations with patients and their parents or carers and might think the chances of having to face such experiences are negligible. This is probably true, but remember that it used to be exceptional for doctors to defend themselves in medical negligence cases. There cannot be many consultant paediatricians active in clinical practice who are untouched by litigation to some degree. A recent paper ${ }^{1}$ drew attention to false allegations of sexual touching and subsequent correspondence included a reference to the suicide of one practitioner so accused. ${ }^{2-4}$ Although these observations are directed towards paediatricians, they apply equally to any doctor whose practice includes children.

\section{Consent}

One should always remember that it is the child or young person who is the patient and the examination should only proceed when consent has been signified. Although it will be the parents' agreement in the case of an infant, it is important to include the older child in the discussion and to obtain the unequivocal assent of an adolescent. For consent to be valid three conditions must be satisfied. First, the patient must have the necessary capacity to give consent; second, the patient should have sufficient infor- mation to make an informed choice, and last, the consent must be given voluntarily.

Competent children can give consent to therapeutic procedures. In the Gillick case, which centred around the provision of contraceptive services to the under $16 \mathrm{~s},{ }^{5} \mathrm{Mrs}$ Gillick's argument was based upon section 8 of the Family Law Reform Act, ${ }^{6}$ which states that children who have attained the age of 16 years can give valid consent to medical, surgical, and dental treatment. She argued that those who had not reached the age of 16 could not give a valid consent to such treatment. The Law Lords (by majority) rejected her argument, stating that it was intellectual capacity, not age, that mattered. As a child matures and is able to understand the implications of accepting or rejecting a particular treatment, so that child has the necessary capacity to consent to the treatment in question. Competence, however, is not an all or nothing phenomenon, but depends upon the child's ability to understand what is proposed in the particular instance. For example, a patient may have sufficient capacity to consent to a straightforward general examination but may lack the capacity to understand what is involved, say, in a genital or rectal examination.

For an individual to make a choice, that individual must have sufficient information to weigh up the pros and cons of the various alternatives available. Many American jurisdictions have adopted the doctrine of 'informed consent', which requires the doctor to disclose all the information that a prudent patient would require before making a decision. In the Sidaway case the House of Lords rejected informed consent theory, placing the onus upon the doctor to ensure that adequate disclosure is given. ${ }^{7}$ Lord Bridge set out the standard as follows:

'What degree of disclosure of risk is best calculated to assist a particular patient to make a rational choice as to whether or not to undergo a particular treatment must primarily be a matter of clinical judgement'.

The Sidaway case also established that doctors should not lie to their patients and, secondly, that information can be withheld in whole or in part if disclosure would be likely to cause severe harm to the mental or physical health of the patient (sometimes referred to as therapeutic privilege). Where a child is not 
competent to consent, any person with parental responsibility may consent on behalf of the child. In emergencies any treatment that is necessary to prevent serious harm to the patient may be given in the absence of consent and failure to do so may give rise to allegations of negligence.

Written consent to examination is usually unnecessary but the wise practitioner does not assume it has been given just because a parent presents their child with a symptom.

With certain examinations, such as after sexual abuse, documentation of agreement and to disclosure of information after examination is a wise practice. The doctor should briefly outline what examination is proposed, how much of the clothing will need to be removed, and answer any questions posed fully. They should check that both parent and child are in agreement as the examination proceeds: if there is a hint of uncertainty or anxiety, the examination should stop until the parties relax again. The findings, especially if negative, should be communicated to the parent and child. The crucial point is that if one is perceived (by speech, demeanour, gentleness, unhurriedness) as having respect for the child and his or her feelings, then difficulties are unlikely to occur.

\section{Refusal of consent}

If the parent declines to allow the child to be examined, then the reasons need to be teased out. Sometimes it must be explained that the clue to the cause of a symptom in one part of the body might lie in a distant part. An example would be palpation of the femoral pulses when assessing a heart murmur. If persuasion fails, then it would be reasonable to offer a second opinion or examination by a different consultant either of the same or different sex as the child, according to the child's, rather than anybody else's, preference. ${ }^{8}$

A more difficult problem arises when a child refuses to consent to an examination and when the parent wishes the examination to be done. With a younger child, parental firmness (carried out within the general framework of civilised parental discipline) may be effective. If this is not the case, then it is unlikely that a clinically useful examination can be done on a totally uncooperative youngster. With a school age child it would be most unwise to force the issue, especially so with older children and adolescents. One might try to use reason but one should not be seen to collude with parents in bribing or other techniques; indeed, great care must be taken to avoid allegations that a consent was not obtained voluntarily. Any degree of fear, force, or fraud may render the consent invalid and the doctor open to allegations of negligence or, in an extreme case, battery. In these circumstances, all one can do is try and obtain the maximum information from the minimum permitted examination and explain and note the limitations that it will impose on one's opinion. It is sometimes useful to explain to an older child what is involved and offer a further appointment after a period of reflection. The legal position is clear. Com- petent adults who refuse specific treatment are entitled to expect that no one will attempt to impose that treatment upon them even if, on an objective basis, the decision they have taken is a poor one and that the treatment is necessary to protect their best medical interests. In the case of $\operatorname{Re} C$ one patient obtained an injunction to prevent doctors amputating a gangrenous limb. After the Gillick judgment it seemed reasonable to assume that the same principle would apply in the case of a competent child, but the case of $\operatorname{Re} R$ (provision of medical treatment to a 15 year old suffering from mental illness) dispelled that theory. ${ }^{9}$ In this case the child was made a ward of court and the Court of Appeal held that the court in wardship had authority to consent to treatment. Lord Donaldson then proceeded to provide a gloss to Gillick by stating that where a child refuses treatment, a parent retaining the authority to consent may consent on the child's behalf. The presence of a valid consent from the parent will not ease the practical difficulties of examining an uncooperative patient. Where the child is incompetent and the parents refuse consent to an examination and it is necessary to protect the best interests of the child, the doctor can if necessary turn to the courts for authority to proceed. In a life threatening situation, the practitioner should act in accordance with the child's best interests, obtaining a second opinion where appropriate, documenting the episode fully in the case notes and communicating with the general practitioner in the expectation of being required to justify his actions in due course.

The giving and receiving of consent in paediatric practice has been written about widely, both in Europe and North America. ${ }^{10-13}$ Most of the literature deals with the wider question of treatment rather than the specifics of physical examination, although the principles are the same. The statement of the American Academy of Pediatrics Committee on Bioethics ${ }^{14}$ touches on conduct of pelvic examination in the adolescent.

\section{Conduct of the examination or procedure}

It is important to convey to the child or young person that a clinical examination is a unique affair in human relationships. The doctor has a privileged responsibility in being able to look at and touch parts of the body that others (including the parents) may not. Without wanting the atmosphere or surroundings to appear intimidating, it might be helpful for this exceptional professional contact to be conducted in a formal way. This will include the explanation of what is to be done and assent or agreement signified. In certain examinations the agreement and consent might be documented.

It is often prudent to have a witness to a clinical examination. With most children it will be the parent who will be a partner in the explanation and preparation for the examination. The parent or carer may themselves have undergone a general physical examination and be aware of what is happening. However, they may not have experienced, say, a rectal examination or the gentle breaking down of prepucial 
adhesions. It is important that such parents are aware of what the doctor is trying to achieve and of the degree of distress and anxiety that may be caused to the child.

Judging the force behind a protesting child is difficult but one should be careful not to be perceived to be causing excessive pain or embarrassment. One should usually ask for a nurse to be in attendance for such examinations. This is not only to fulfil the chaperoning function, but also their participation in the examination will reassure the parent or carer that the procedure is an acceptable part of clinical paediatric practice.

Older children might prefer the parent not to be present when the examination is taking place. Here it is essential that a chaperone is present; indeed in some consultations with older children on their own or some parents it is wise to have a witness present during discussions as well as the examination so that subsequent criticism may be rebutted. Although time honoured allegations of sexual indiscretion have been between a male doctor and female patient, one should not overlook the possibility of complaints from patients of the same sex as the doctor or from male patients against female doctors.

\section{A problem?}

If one senses that the examination has caused distress to the child and parent to a greater degree than had been anticipated, it is important to discuss the matter at the time. Such occurrences are usually minor and result from a misunderstanding. Again, it is important to have a witness who may themself be able to contribute constructively to the discussion. Documentation is important and the offer of a second opinion helpful. A telephone call to the general practitioner might explain things and help if the parent consults them.

\section{A complaint}

A complaint may be made at the time of the examination, in writing to the hospital manager some time later, to the police, to the General Medical Council, or to a combination. The complaint may arise from an incident that the paediatrician might recall and which had been dealt with by explanation and thorough documentation. Alternatively, the complaint may arise from a consultation where nothing appeared to go wrong at the time. In these cases there will be little in the case record other than the documented examination. The records must not be altered subsequently. A later dated entry-if required-would be acceptable provided that it was made clear that it was not a contemporaneous record and that there is nothing that might be misconstrued as falsifying the record. Assuming that the allegation is untrue, then it will usually have arisen because of a misunderstanding, misjudgment or, possibly, through malice. The response of the paediatrician is likely to be of incredulity, anger, paranoia, and some hostility. These are understandable and to be expected. It is unwise to make personal contact with the parents (and certainly not with the patient) outside the machinery for dealing with the complaint. Advice should be obtained from the defence society and, if the employer's disciplinary procedures follow, the British Medical Association or another professional representative body. It is important to cooperate with the inquiries, subject to legal advice, and, if requested, meet with the complainant. In this way complaints resulting from misunderstanding may be resolved speedily.

In these unpleasant situations it is important to have personal support. Some doctors tell nobody that it has happened. This is particularly unfair on one's spouse or partner who might bear the brunt of moody introspection. Close colleagues and one's general practitioner will undoubtedly provide support and should be used: offers of a brief period of leave might be taken up. However, the temptation to abandon practice because of an isolated mischievous allegation is understandable but should be resisted.

If the complaint is true then the matter becomes more serious because of the harm to the child. One's primary duty as a doctor is to the patient, who will come to least harm by a frank admission and perhaps be spared adversarial legal proceedings.

\section{A colleague}

Informing on one's colleagues might appear distasteful and has certainly not been part of the general medical culture. However, the welfare of patients is paramount and if there are suspicions about a colleague's demeanour or conduct then it is unjustifiable to ignore them. A face to face confrontation is likely to be painful and one would sympathise with those who wished to avoid it. We believe, however, that the profession would be healthier with this frank and honest approach and encourage the practice when others are concerned about another's competence, conduct, or health. One must avoid being drawn into a collusive concealment exercise out of well intentioned but misplaced sympathy. Discussion with close colleagues and documentary evidence would be useful. The matter should be discussed with the chairman of a professional medical committee and the medical adviser to the employer (the medical director of an NHS trust) who should take responsibility for action.

In the UK doctors who avert their eyes to such behaviour will be putting themselves in jeopardy with the General Medical Council whose recent advice is: 'You must protect patients when you believe that a colleague's conduct, performance or health is a threat to them'. 'Before taking action, you should do your best to find out the facts. Then, if necessary, you must tell someone from your employing authority or a regulatory body. Your comments about colleagues must be honest. If you are not sure what to do, ask an experienced colleague. The safety of patients must come first at all times'. ${ }^{15}$

\section{Conclusion}

Allegations of assault are uncommon. With clear communication and sensitivity between 
doctor, patient and parent, they are probably avoidable in the majority of cases. However, prevention is better than cure and the foresighted use of witnesses, chaperones, and second opinions may forestall them. Clear, decipherable communication and contemporaneous notes are imperative to allow doctors and their advisors to conduct a robust defence in any subsequent complaint or allegation.

1 Silber TJ. False allegations of sexual touching by physicians in the practice of pediatrics. Pediatrics 1994; 94: 742-5.

2 Kaplan J. False allegations of sexual touching. Pediatrics 1995; 95: 797.

3 Ricci LR. False allegations of sexual touching. Pediatrics 1995; 95: 797 .

4 Silber TJ. False allegations of sexual touching. Pediatrics 1995; 95: 797-8.
5 Gillick v West Norfolk and Wisbech Area Health Authority [1986] AC 112; [1985] 3 All ER 402; [1985] 3 WLR 830 6 Section 8 of the Family Law Reform Act 1969, page 5 re C (mental patient: medical treatment) [1993] BMLR 15, 77, fam $D$.

7 Sidaway. The Governors of Royal Bethnal Hospital [1985] 1 All ER 643 .

8 Neinstein LS, Shapiro J, Rabinovitz S, Baer K, Church J, Sasao T. Comfort of male adolescents during general and genital examination. $\mathcal{F}$ Pediatr 1989; 115: 494-7.

$9 \operatorname{Re} \mathrm{R}$ (a minor) (wardship: medical treatment), re [1991] 4 All ER 177.

10 Devereux JA, Jones DPH, Dickenson DL. Can children withhold consent to treatment? $B M \mathcal{F}$ 1993; 306: 1459-61. withhold consent to treatment? BMf 1993; 306: 1459-61.
Elton A, Honia P, Bentovim A, Simons J. Withholding consent to lifesaving treatment: three cases. BMF 1995; 310: 373-7.

12 Shield JPH, Baum JD. Children's consent to treatment. BMF 1994; 308: 1182-3.

13 Gaylin $\mathrm{W}$. The competence of children: no longer all or none. Hastings-on-Hudson, New York: Hastings Center Report, 1982; April: 33-8.

14 American Academy of Pediatric Committee on Bioethics. Informed consent, parental permission and assent in pediatric practice. Pediatrics 1995; 95: 314-7.

15 General Medical Council. Good medical practice. Duties of a doctor. London: General Medical Council, 1995: paras 18,19 .

\title{
When is HIV an issue after child sexual abuse?
}

\author{
Jacqueline Y Q Mok
}

Child sexual abuse is an increasingly recognised problem, the complications of which include a small, but real risk of acquiring infection with HIV. The incidence of HIV infection acquired by children through sexual abuse is unknown. Sexual abuse does not appear as a separate transmission category among the cases of HIV infection reported to the British Paediatric Association Surveillance Unit. However, there is a rising incidence of young adults reported with HIV infection in the UK, some of whom could have acquired the infection as a result of sexual abuse. Children and young people have an awareness of HIV and AIDS and are taught about harm minimisation and healthy living to reduce the risk of HIV infection. Health promotion and personal safety programmes in schools have, in turn, led to disclosures of abuse in children. Sexual abuse and HIV evoke strong emotive reactions, but there are also difficult and complex issues that need to be addressed. The greatest demand for HIV testing comes from professionals working with children and adolescents who have been sexually abused, including vulnerable young people who may be survivors of abuse. As yet, most guidelines on child protection do not discuss whether HIV testing should be performed, although some professionals working with children who have been sexually abused have made some recommendations on HIV testing. ${ }^{2}$ Recent government guidance on children and HIV also raises the possibility of HIV infection where children have been sexually abused. ${ }^{3}$

\section{Are the concerns valid?}

Sexual abuse is a documented mode of transmission of HIV, although reports are anecdotal. ${ }^{45}$ It is conceivable that traumatic abuse involving penetration would increase the risk of HIV transmission by mucosal breach, and the immature anogenital tract might be more vulnerable to infection. In an attempt to determine the incidence of HIV infection acquired through sexual abuse, a telephone survey was conducted of 63 practitioners who see sexually abused children in five regions in the United States with the highest prevalence of HIV infection. No formal protocol was in place for HIV antibody testing of abused children. In approximately $1000 \mathrm{HIV}$ antibody tests performed by the practitioners, HIV infection was discovered in two children in whom no other cause for infection was identified. ${ }^{6}$ In a further survey of 2147 health and social service professionals involved with child abuse assessment, the authors found that 5622 HIV antibody tests were conducted during 113198 sexual abuse assessments. Twenty eight children were found to be infected with HIV and had no alternative transmission route other than sexual abuse, a crude rate of 0.25 per 1000 assessments.

Although most children who have been abused cope well with no long term effects, it is acknowledged that for many survivors, the experience can result in activities which may predispose the young person to HIV infection. ${ }^{89}$ Characteristics of the child sexual abuse survivor have included sexual compulsivity, revictimisation, and low self esteem with chronic depression, ${ }^{10}$ which may lead to alcohol and drug abuse, exposing the adolescent to HIV infection. On the other hand, recognised high risk behaviours for HIV infection are found among many homeless teenage 